\title{
UTOPIA E IDENTIDADE: UMA NAÇÃO PARA O DESERTO
}

\author{
Eugênio Rezende de Carvalho*
}

\begin{abstract}
Se der crédito às tradiçōes. aliás plenamente justificadas pela configuração do pais, esta terra não foi sempre una itha. Chanava-se antigamente Abraxa e se ligava ao continente: Utopus apoderou-se dela, e deu-lhe seut nome.

Este conquistador teve bastante gênio para humanizar uma populaçăo grosseira e selvagem e para formar um povo que ultrapassa hoje todos os outros em civilizaçâo. Desde qute a vitória o fe dono deste pais. mandou cortar am istmo de quinze mil passos no lado em que está ligado ao continente; e a terra de Abraxa tornot-se. assim, a ilha da Utopia.
\end{abstract}

Rafael Hitlodeu. personagem da Utopia de Thomas More

\section{Resumo}

Esse artigo explora o conteúdo utópico de Argirópolis, obra do argentino Domingo Faustino Sarmiento (1811-1888), publicada em 1850, na qual se propunha a reunião, sob a forma dc uma Confederação, do que fora outrora o antigo Vice-Reinado do Rio da Prata - cujo território compreendia a Argentina. Uruguai, Paraguai e parte da Bolivia atuais. Tal união teria como base a criaçâo de um Congresso Geral. uma Constituição unilicada e a construção de uma nova capital em local "neutro" - no caso, na ilha de Martín García - que se chamaria Argirópolis, ou "cidade do - ou da - Prata". Para além da aparência e do textual, de onde sobressai o panfleto politico de cunho liberal e panfletário, o que se quer demonstrar nesse trabalho é como que a utopia de Argirópolis sintetizava e simbolizava a idéia ou o desẹjo de uma nova nação para o "deserto" argentino. de uma nova identidade para o contexto platino.

Palavras-chave: Sarmiento: Argirópolis: Argentina: identidade

* Mestre em História pela Universidade Federal de Goiás. Doutorando em História na Universidade de Brasilia (UnB). 


\section{Introdução}

Para muitos a América foi e continua sendo um espaço privilegiado para a concretização das utopias, sejam próprias ou alheias. $\mathrm{Na}$ hispano-américa do século XIX as utopias fervilhavan entre a intelectualidade, sobretudo aquelas que aspiravam a concretização dos ideais de identidade e nação. É nesse momento que se destaca em Buenos

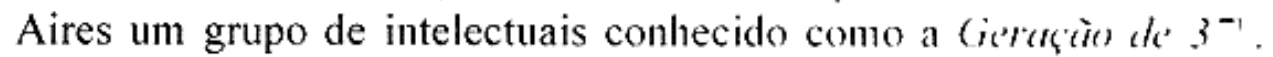
Deslumbrados pelas idéias do iluminismo francès. tomavam para si a grande missão de modelar a sociedade à razão, de promover os ajustes sociais tão prementes. Pregavam sua fé na perfectibilidade e no contínuo progresso da humanidade. Assim, armados com a razão, consideravam o futuro algo planejável e previsível, desde que conhecidas as "leis" que regiam a ordem social. Complementavam ainda o universo ideológico dessa geração as doutrinas liberais e humanitárias da época. Nesse contexto de idéias e influências ganha destaque a figura de Domingo Faustino Sarmiento (1811-1888) com seus projetos de transformação e a crítica da realidade social platina.

Uma condição, no entanto, marca profundamente os intelectuais dessa geração de 37 e sobretudo Sarmiento: o exílio. A história tem fornecido inumeráveis exemplos de como os indivíduos no exílio tendem, na sua exterioridade, a uma reflexão profunda sobre suas próprias raízes: a privação de um solo e de uma pátria impõem a sua reivindicação. Um dos antídotos encontrados para o vazio do exílio foi a literatura: através dela buscou-se preencher esses espaços, construir nações e nacionalidades. Assim, do exílio formularam-se utopias e identidades. E foi no exílio que Sarmiento produziu suas principais obras.

Em 1850, Sarmiento empreendia um balanço da difícil conjuntura vivida pela região em torno da bacia do Rio da Prata. Lamentava as intermináveis guerras em torno da disputa pelo livre direito de navegação nos rios; as guerras civis entre caudilhos, unitários e federais, bem como as desigualdades de riquezas entre os países e províncias do litoral e do interior. Tais eram os fatores que comprometiam a livre navegação dos rios - fonte de comércio e riquezas -, a independência e a prosperidade das nações e províncias da região. Como solução para esse quadro caótico Sarmiento propõe a reunião, sob a forma de uma Confederação, do que 
fora outrora o antigo Vice-Reinado do Rio da $\operatorname{Prata}^{2}$, união esta que teria como base a criação de um Congresso Geral, uma Constituição unificada e a construção de uma nova capital em local "neutro", no caso, numa ilha de possessão francesa situada na embocadura do Prata, chamada Martín García. À nova capital Sarmiento daria o nome de Argirópolis, ou "cidade do - ou da - Prata".

Em resumo, este seria seu projeto, que foi transformado em livro, publicado em 1850, que levou o nome de Argirópolis. E é seu conteúdo que procuraremos explorar neste trabalho. Ä primeira vista sua leitura nos dá a impressão de tratar-se de uma mera proposta política, de cunho liberal e panfletário. O que queremos demonstrar é que, por trás da aparência textual de um mero panfleto político, o texto apresenta um conteúdo essencialmente utópico. Embora o conceito de utopia seja polissêmico, invariavelmente as perspectivas utópicas têm em comum a reivindicação de um "mundo alternativo". Independentemente da concretização ou não do projeto utópico, cremos na força da utopia como instrumento de crítica do mundo real e presente, na força crítica contida na sua contra-proposta. Em Argirópolis encontramos claramente esse binômio crítica-proposta ${ }^{4}$. Suas páginas revelam uma contundente crítica ao contexto social platino da época. O projeto utópico assume aqui um sentido "patológico". O utopista, dotado da capacidade e autoridade de um "médico" - quem tem a razão e a ciência às mãos -, se debruça sobre um corpo social "enfermo" - imperfeito, indesejável-, estabelece o diagnóstico dos males sociais; prescreve o estado da "boa saúde" - a boa sociedade - e propõe a terapêutica - os meios para alcançar a sociedade alternativa ideal, de realização plena do "bem comum" e da "felicidade geral". Diga-se de passagem que este tratamento "científicopatológico" do corpo social - extensão da biologia ao campo da sociedade - era um procedimento típico adotado pelos intelectuais argentinos contemporâneos de Sarmiento.

Por fim, o que queremos demonstrar nas linhas que seguem é que para além da aparência e do textual, a utopia da Argirópolis de Sarmiento visava no fundo propor uma nova nação para o "deserto" argentino, enfim, propor uma nova identidade para o contexto platino. 


\section{O utopista: intelectual-profeta?}

Ao apresentar seu projeto utópico, Sarmiento terá uma grande preocupação em fundamentá-lo sob todos os meios possiveis, para dotálo do mais alto índice de confiabilidade e legitimidade. No longo subtítulo da obra, o autor apresenta uma espécie de síntese do seu conteúdo. Vale a pena reproduzi-lo aqui:

Solución de las dificuldades que embarazam la pacificación permanente del Rio de La Plata, por medio de la convocación de un congreso, y la creación de una capital en la Isla de Martín García, de cuya posesión (hoy en poder de la Francia) dependen la libre navegación de los ríos, y la independencia, desarrollo y liberdad del Paraguay, el Uruguay y las provincias argentinas del litoral. (p. 11)

A julgar por este subtítulo, a primeira impressão que temos é de que se trata de uma proposta política que pretende por fim às guerras que assolam a região platina, originadas em torno do direito à livre navegação de seus rios, por uma saída liberal. "Pacificar" é condição para trazer desenvolvimento material, independência e liberdade comercial - para todos os países e províncias do Prata. A convocação do Congresso e criação da nova capital aparecem como os meios para se atingir esse fim. Mais à frente, na Introdução, o próprio Sarmiento apresenta explicitamente seus objetivos:

El presente opúsculo há sido escrito com la mente de sugerir, por el estudio de los antecedentes de la lucha, la geografia del país, y las instituciones argentinas, un medio de pacificación que a la vez ponga término a los males presentes, y ciegue en su fuente la causa de nuevas complicaciones, dejando definitivamente constituidos aquellos paises. (p. 13)

Aqui Sarmiento fala com a autoridade do "científico", que embora esteja apenas "sugerindo" um meio de pacificação, o faz mediante o respaldo de um estudo prévio dos contextos históricos, geográficos e políticos. Esse "estudo" racional da realidade permitirá a descoberta das "fontes", das verdadeiras "causas" dos males presentes. O uso da 
razão legitima o diagnóstico e dá força à receita. Note-se a sutil preocupação com a "constituição definitiva" daqueles países.

Mas para legitimar de vez sua proposta, Sarmiento lança mão de novos argumentos, supostamente mais convincentes, mesmo não obedecendo os mesmos critérios de "racionalidade" dos anteriores. Chama a atenção do leitor de Argirópolis as notas que acompanham o subtítulo já citado acima, que assumem mais uma função de epígrafe. São duas notas. A primeira, uma citação bíblica (Evangelho de São João) cujo tema são as pregações públicas de Jesus. Da segunda, por sua vez, de Pablo Luis Courier, extraímos esta parte:

No es solo un derecho, es una obligación estrecha de cualquiera que abriga una idea el publicarla, y darla à luz para el bien comum. La verdad por entero pertenece a todos. Aquello que sabéis y es útil y digno de que todos lo sepan, no podéis ocultarlo en conciencia. (p. 11)

O curioso é que no Livro Segundo d'A Utopia de Thomas More, que trata da "Comunicação de Rafael Hitlodeu", encontramos também, a título de epígrafe, a seguinte citação bíblica: "O que vos digo em voz baixa e ao ouvido, pregai-o em voz alta e abertamente". (Mateus, 10,27) Sarmiento se apresenta aqui como portador de uma verdade, desconhecida pelo resto dos mortais, e sua "obrigação" é fazer com que seja propagada a todos para a concretização do "bem comum". Se apresenta como um privilegiado com uma grande missão por realizar; porta-voz eleito por Deus e pela razão, e, por isso, dotado de toda a autoridade. Assume as características do tipo do "intelectual-profeta". (Rodriguez Pérsico, 1993: 06) No afă de definir os parâmetros de uma sociedade alternativa bem como os meios de alcançá-la, busca legitimar seu projeto evocando, entre outros argumentos, esta autoridade delegada, divina, e, portanto, inquestionável. Sua grande preocupação seria nesse momento cobrir sua proposta de legalidade - pelo direito natural e escrito a que recorrerá com freqüência - e, principalmente, de legitimidade pelo mandato recebido. Nas linhas da sua Introdução ele se preocupa em afastar qualquer sentimento de hostilidade, buscando acima de tudo o "consenso", procurando colocar-se por cima de todas as facções e interesses em pugna. Somente com a autoridade inquebrantável de um 
"intelectual-profeta" poderia cumprir esse papel de guia e conciliador, capaz de terminar a guerra, construir o país, acabar com as animosidades, conciliar interesses divergentes etc. (p. 14) Na qualidade de profeta seria capaz ainda de prever um futuro luminoso para a contexto platino, acreditando estar cumprindo o dever "que nos impone la sangre argentina que corre por nuestras venas." (p. 16) E é dotado dessa autoridade, desse poder de impor o consenso e de falar em nome do interesse coletivo, que empreende um chamamento à unidade regional. $\mathrm{O}$ cimento dessa unidade era não só afinidades como religião, costumes, clima, idioma, mas, sobretudo, qualquer coisa que possuísse a marca da civilização: como por exemplo "pessoas civilizadas", em particular, imigrantes europeus. Segundo Sarmiento já era passada a hora de a América do Sul, a exemplo da América do Norte, se preparar para receber aqueles que, trazendo consigo modos de vida civilizados, contribuiriam para nela edificar uma grande nação.

\section{Argumentos Textuais para a Criação de Argirópolis}

Creemos haber llegado a establecer solidamente la conveniencia, la necesidad y la justicia de crear una capital en el punto céntrico del Rio de la Plata, que poniendo por su posición geográfica en harmonia todos, los intereses que se chocan sin provecho después de tan largos años, termine a satisfación de todos los partidos, de todos los Estados del Plata la guerra que los desola, para cuya solución han sido impotentes las armas de la Confederación Argentina y la diplomacia europea. (p. 68)

Sarmiento lamentava, incansavelmente, que a República e a Confederação Argentina nunca haviam reconhecido uma capital. Procura em seu texto estabelecer alguns parâmetros sobre os quais deveria se pautar a escolha de um local para a capital da Confederação que ele propunha criar. Admitia inclusive que, caso não se encontrasse um local apropriado no rio da Prata, dever-se-ia "inventar" um que estivesse protegido de toda conexão e influência dos diversos estados. Mas era conveniente, necessário e justo a criação de uma capital em um ponto cêntrico do Prata, que pela sua posição geográfica fosse capaz de 
harmonizar interesses conflitantes. Nosso utopista estava convicto que tal local já existia: era a ilha de Martín García, situada na confluência dos grandes rios da bacia do Prata. Sua possessão interessaria igualmente a Buenos Aires, a Montevidéu, ao Paraguai, a Santa Fé, Entre Rios e Corrientes, cujo comércio estava subordinado ao trânsito sob as fortalezas dessa ilha. Ocupando-a o Congresso, a ocupariam ao mesmo tempo todas as províncias, todas as cidades interessadas, todos os estados confederados. Era o meio de garantir a liberdade comercial de todos os estados contratantes. Liberdade comercial que garantiria prosperidade, riqueza, dinheiro, daí a justificativa do nome "cidade da prata".

Em apoio a criação de uma capital em Martín García, para "conciliar os interesses e a liberdade dos estados confederados", Sarmiento apresentava então os seguintes argumentos que ora passaremos a analisar.

O primeiro ponto de apoio à tese da nova capital é o exemplo da cidade de Washington, que fora escolhida como capital em detrimento de Nova York - cidade mais rica e populosa à época - com o objetivo de não aumentar ainda mais a desproporção de poder e influência que existia naturalmente entre Nova York e Boston, Baltimore, Filadelfia etc. Sarmiento afirma que Martín Garcia cumpriria ainda melhor que Washington esse importante papel de centro administrativo da união por sua condição insular. E exatamente esse caráter insular seria mais outro forte ponto de apoio à capital proposta, pois facilitava a manutenção de sua neutralidade, protegendo-a das influências de qualquer uma das províncias e países da União.

A fim de justificar as vantagens de uma Confederação para os três Estados - Confederação Argentina, Paraguai e Uruguai -, Sarmiento dedica a este ponto todo um capítulo do livro. Procura chamar a atenção daqueles que seriam os reais interessados na convocação de um Congresso Geral, que fosse capaz de por fim à luta que por tantos anos manchava de sangue as margens do Prata. Procura conduzir seu raciocínio no sentido de convencer seus destinatários - os governos das nações envolvidas - de que o destino natural do Paraguai e Uruguai seria juntarem-se à Confederação Argentina, numa grande federação entre os três países, para a qual sugeriu o nome de "Estados Unidos de la América del Sud". Para ele, a concorrência predatória praticada entre Buenos 
Aires e Montevidéu, situadas na embocadura do Prata, levaria ambas inexoravelmente à ruína. Com a União, todos levariam vantagens, inclusive o Paraguai e Uruguai. Reafirma sua certeza de que, com tal solução, estaria findado o período de lutas fratricidas entre estados que deveriam ser florescentes.

La Confederación Argentina, el Paraguay, y la República del Uruguay, están en fin dependientes de la posesión de la isla de Martín Garcia, que es la llave del comercio del Uruguay y del Paraná, y por tanto de los intereses de Montevideo, Buenos Aires, Santa Fé, Corrientes, Entre Ríos, el Paraguay y todas las provincias enteras. (p. 38)

Garantindo o pacto de união e federação estaria o Congresso Geral, que seria capaz de atender a todos os interesses, garantindo a liberdade política e comercial desses países. Para Sarmiento, o Congresso seria um dos meios capazes de garantir o consenso e o ponto de equilibrio entre os distintos interesses.

Outro ponto em defesa da tese da nova capital seria a condição estrangeira da ilha, ou seja, o fato de que a ilha não era de propriedade de nenhum dos países da rẹião do Prata, o que acabava por reforçar sua neutralidade: se não era de ninguém, poderia ser de todos, já que a França não se negaria a devolvê-la a um Congresso, segundo acreditava Sarmiento.

Também contribuiria com a criação de Argirópolis o fato da posição geográfica das províncias da Confederação Argentina favorecerem a posição de Martín García como centro administrativo e alfândega geral. Isto porque na República Argentina, a distribuição da riqueza - também do poder e da civilização - não era proporcional. Enquanto Buenos Aires se beneficiava de vantagens comerciais por conta da sua localização geográfica, ligada que estava diretamente ao comércio europeu, os pontos mais distantes da costa estavam condenados à ruína frente aos altos custos de exportação. $O$ interior ficava interditado ao comércio europeu. Por isso, o porto de Buenos Aires não era a via que a própria natureza indicara para a cômoda exportação dos produtos do trabalho dos povos do interior. Já Martín García, ao contrário, possibilitaria uma maior conexão dessas províncias interioranas com o 
comércio exterior, sendo por isso o local escolhido pela própria natureza para sediar a capital da federação. Sarmiento partilhava a idéia - para ele lei universal - de que a riqueza e prosperidade das nações - e, portanto, seu poder - derivariam da facilidade de suas comunicações interiores, da quantidade de portos em contato com o comércio das outras nações. E no caso específico da região, os rios eram tudo.

Toda la vida va a transportarse a los rios navegables, que son las arterias de los Estados, que llevan a todas partes y difunden a su alrededor movimiento, producción, artefactos; que improvisan en pocos años pueblos, ciudades, riquezas, naves, armas, ideas. (p. 15)

Continuando a listagem dos argumentos em favor da nova capital, Sarmiento sustenta a possibilidade de manutenção das vantagens comerciais entre Buenos Aires e Montevidéu, com a fixação de uma legislação comum, o que eliminaria a rivalidade comercial entre ambas cidades, fonte de tantas guerras. Outro fator seria a possibilidade de se criar em pouco tempo um importante centro comercial na ilha, comum a todas as outras cidades, o que seria, por si só, um novo elemento de prosperidade.

Por fim, o Congresso Geral, a ser instalado na ilha, garantiria maior estabilidade a todas as províncias e repúblicas, num contexto em que a instabilidade e a guerra contínua - no momento contra a província Oriental, o Uruguai - arrasavam a região platina, retirando o sangue e a fortuna de seus povos. Este Congresso, aliás - argumenta Sarmiento -, por acordos anteriores, já deveria ter sido convocado, o que não aconteceu devido à ação dos governos de Buenos Aires de protelar tal decisão, já que a manutenção do atual estado de coisas mantinha as demais provincias sob sua dependência. O Congresso federativo deliberaria sobre os comércios interior e exterior, sobre a cobrança e distribuição das rendas gerais, e, principalmente, sobre navegação.

El congreso, en fin, dirá si el rio de la Plata es el hijo predilecto de la confederación, y si el Paraná, el Uruguay y el Paraguay deben permanecer siempre fuera de la ley de la distribución eqüitativa de las ventajas comerciales de la asociación. (p. 62) 
Sarmiento destaca ainda as transformações operadas na ordem política como efeito da criação do Congresso Geral e da nova capital. $\mathrm{O}$ resultado, para ele, seria a afirmação de uma "lei comum e definitiva dos povos" que afastariam de vez da cena política o espantalho dos unitários (p. 80). Ou seja, a opção federal eliminaria os pretextos unitários para sempre.

Facilitar as vias de comércio exterior, que era um dos fins propostos, implicava em estabelecer novos parâmetros norteadores das relações entre a Europa e o Rio da Prata. Sarmiento se mostrará preocupado em demonstrar a confluência de interesses, perfeitamente conciliáveis entre si, entre as potências européias e os países do Prata. Para ele, não haveria por parte da França e Inglaterra, pelo menos naquele momento, interesses de conquista. Não via, portanto, nenhuma ameaça à independência dessas nações americanas. A Europa só desejava vender a maior quantidade possível de suas mercadorias e explorar a maior quantidade possível de produtos americanos. Não haveria razão para conflito, pois

...nosotros no seremos fabricantes sino com el lapso de los siglos y com la aglomeración de millones de habitantes: nuestro medio sencillo de riqueza, está en la exportación de las materias primeras que la fabricación europea necesita. (...) en este punto, pues, nuestro interés es casi el mismo que el de las potencias europeas, y bastarian algunas leyes inteligentes y previsoras para que se armonizasen del todo. (p. 85)

Uma vez que a região do Prata levaria séculos para ser industrializada, caberia a ela tirar o maior proveito possível de uma condição de mera fornecedora de matérias-primas para a indústria européia, numa aceitação tácita das relações criadas pela divisão internacional do trabalho, imposta pela ordem econômica capitalista mundial.

Em suma, todas esses pontos citados em apoio à criação do Congresso Geral e da nova capital da Confederação tinham como objetivo último facilitar as vias de comunicação entre as províncias e os portos, favorecendo o comércio interior e exterior. Tais medidas seriam a garantia de um futuro próspero para todas as províncias e países da região. 
Essa "reunião das forças coletivas" seria capaz de garantir então grandes vantagens a cada estado associado.

E uma vez solucionada esta questão, o futuro, entrevisto pelo "intelectual-profeta" só poderia ser grandioso:

Pocos años bastarán para que habilitadas estas grandes arterias destinadas por la Providencia a llevar el movimiento y la vida a todos los extremos de la República, nuevos territorios serán poblados, mayor número de ciudades riberanas creadas, haciendo com la misma masa de productos exportados, la prosperidad de todas ellas, y ensanchando la esfera de las especulaciones de Buenos Aires y Montevideo, cuya situación aventajada las hará siempre florescientes. (p. 66)

Até aqui podemos concluir, pelas aparências, que o texto se resume a um belo e precioso exemplar de tratado político em defesa do liberalismo econômico. Sem dúvida que a utopia sarmientina de Argirópolis guarda um forte componente liberal. As conecções entre a ideologia liberal e sua estrutura utópica são evidentes. Cerutti Guldberg (1991) nos lembra que no século XIX o liberálismo culmina um de seus ciclos intelectuais mais fecundos em utopia. No entanto, na seqüência, o próprio Sarmiento lançará mão de outros argumentos em defesa da sua Argirópolis, reveladores de que seu projeto utópico liberal tinha ainda outros desdobramentos.

\section{Outros Argumentos em favor de Argirópolis}

Os argumentos no âmbito da racionalidade econômica e política pareciam quase que esgotados e mais do que suficientes para a legalizar e legitimar a proposta de Argirópolis. No entanto, a necessidade imperiosa da fusão pacífica dos três Estados, somente possível com a convocação do Congresso e com a promulgação de uma nova Constituição - que teria a função de regulamentar as novas relações entre estes Estados - era agora evocada em nome de uma espécie de "destino comum", de "espírito da época", numa reação à antiga "propensão" destas repúblicas à fragmentação, desde as lutas de independência. É como se uma espécie de "voz oculta", sobrenatural, 
estivesse chamando a todos os Estados do Prata a formar um só corpo. Tais argumentos tinham o efeito prático de afirmar ainda mais sua autoridade, dando maior crédito a sua proposta e eliminando qualquer possibilidade de questionamento.

Militan en favor de la fusión de los tres Estados del Plata en uno solo cuerpo, el espíritu de la época y las necesidades de las naciones modernas. La especie humana marcha a reunirse en grande grupos, por razas, por lenguas, por civilizaciones idénticas y análogas. ( $p$. 70)

Os "novos tempos" indicavam o caminho da unidade. A "espécie humana" como um todo caminhava nessa direção. Para completar, Sarmiento buscava ainda exemplos e analogias das outras ciências para demonstrar a racionalidade e as "vantagens da união".

O otimismo de Sarmiento quanto ao futuro promissor dos povos do Prata era marcado também pelo reconhecimento e enaltecimento do potencial das riquezas naturais da região. Ora, se o espaço platino era então mais rico até que o dos Estados Unidos do Norte, era chegado o momento da "raça espanhola" da América do Sul declarar sua dignidade e se apresentar ao mundo como uma grande nação, unificada, capaz de rivalizar em poder e progresso com os próprios anglos-saxões. Sarmiento chegava a entoar um certo determinismo geográfico, embora de forma bastante contraditória. Ao apontar como vantagens as irregularidades geográficas da ilha de Martín García ele retoma a tese de que a grandeza dos povos é proporcional às dificuldades que eles têm a vencer. Segundo sua visão, os pampas, por conta do alimento fácil do pastoreio, só poderia produzir homens indolentes. Mas ao mesmo tempo ressalta que a região de Entre Rios teria, segundo ele, a disposição para ser o país mais rico do mundo, já que a natureza não teria criado espaço de terra mais privilegiado. O problema era que em "seus jardins regados pela natureza" pastavam vacas. A solução era substituir as vacas por homens laboriosos; ao invés de criar vacas, criar cidades e população. Caso se garantisse "leis inteligentes de navegação" essa região seria no futuro um verdadeiro "paraíso terrenal", centro de poder e riqueza. Assim como Martín García era o local da utopia urbana, Entre Rios constituía-se como a zona de realização da utopia agrária. Cidade e campo nessa perspectiva, 
aproximavam-se numa relação de complementariedade. (Rodriguez Pérsico, 1983: 83)

Entre estes outros argumentos apresentados por Sarmiento, que extrapolavam a esfera do econômico e do político, acreditamos que o parágrafo abaixo sintetiza uma das mais importantes idéias contidas em todo o texto e que serve de reforço ao que pretendemos demonstrar no âmbito desse trabalho. Vejamos.

Tal es la influencia que ejerceria sobre los habitos nacionales esta sociedad echada en el agua, si es posible decirlo, y rodeada necesariamente de todos los medios de poder que da la civilización. A nadie se ocultan los defectos que nos há inoculado el genero de vida llevado en el continente, el rancho, el caballo, el ganado, la falta de utensilios, como la facilidad de suplirlos por medios atrasados. ¡Qué cambio en las ideas y en las costumbres! $\mathrm{Si}$ en lugar de caballos fuese necesario botes para pasearse los jóvenes; si en vez de domar potros, el pueblo tuviese allío que someter com el remo olas alborotadas; si en lugar de paja y tierra para improvisarse una cabaña, se viese obligado a cortar a escuadra el granito! El pueblo educado en esta escuela seria una pepinera de navegantes intrépidos, de industriales laboriosos, de hombres desenvueltos y familiarizados com todos los usos y medios de accion que hacen a los norte americanos tan superiores a los pueblos de la América del Sud. (p. 78)

O argumento central aqui é a mudança de idéias e costumes que seria proporcionada pelo novo espírito que seria disseminado a partir de Argirópolis. No continente encontramos um modo de vida "gaúcho", gestado na vida no rancho e na criação de gado, uma cultura cheia de "defeitos", com seus costumes, tradições e forma de pensar bárbaros. Haveria que negar essa identidade original e construir outra. $O$ novo "modo de vida" engendrado pelas correntes de homens industriosos como os norte-americanos teriam o mesmo efeito das águas sobre o deserto. Ondas e ondas de novas idéias e costumes que serviriam para lavar o pecado bárbaro. Sobre a imensidão do deserto então haveria de se construir uma nova "nação das águas". Os únicos elementos efetivamente "nacionais" não poderiam contribuir no entanto com a identidade nacional. Se, por um lado aceitamos a tese de que a identidade não é 
preexistente ao discurso que a nomeia, isso não é suficiente para impedir que aquele mesmo que a nomeie, a negue. E se, por outro lado, aceitamos a preexistência de uma identidade gaúcha constituída ao longo de anos de intercâmbios e vivências comuns ${ }^{6}$, embora possa ser igualmente negada ou não reivindicada como expressão do elemento que simbolize a nação que se quer construir, esta identidade nativa poderia ser simplesmente reeducada conforme os novos padrões das sociedades civilizadas. E era isso o que propunha Sarmiento.

\section{Povoar o Deserto: Construir uma Nação}

Construir uma nação foi uma preocupação que sempre acompanhou Sarmiento e está presente no texto a todo momento. León Pomer ${ }^{7}$ afirma que o grande problema de Sarmiento e da própria geração de 37 , da qual fazia parte, era buscar as respostas às questões de como construir esta nação, por que meios, a partir de que referenciais - algum modelo ou algo totalmente novo? $-\mathrm{e}$, por fim, o que fazer com o existente. Sarmiento, num artigo de $1856^{\circ}$, fazia uma avaliação de que a independência do Vice-Reinado do Rio da Prata teria surpreendido e interrompido um processo em curso de integração entre suas partes, eliminando entre os seus membros um sentimento de adesão responsável pela nacionalidade. Quando veio a revolução estes povos não puderam evitar a desintegração. O que Argirópolis deixa claro é seu desejo de ver unificado o que antes fora o Vice-Reinado do Prata. Era preciso fazer o que a revolução prematura não havia logrado: construir nações verdadeiras. A grande e exclusiva tarefa dos governos independentes deveria ser então a de transformar essa grande extensão de país num Estado. Transformar os rios em meios privilegiados de comunicação e exportação e essa reduzida população uma grande nação.

Sarmiento considerava a República Argentina um grande deserto despovoado, metáfora esta partilhada por toda a elite intelectual de 37. Tendo como pano de fundo a imagem essa imagem do deserto, as preocupações da intelectualidade se voltavam para projetos de formação de identidades e nacionalidades. Como uma das mais drásticas heranças coloniais, a imensidão do deserto impunha aos grandes homens públicos, preocupados em criar uma nação, a nobre tarefa de preenchê-lo. Assim, formar uma nação no deserto implicava em povoá-lo. Mas com quem? 
A população existente era bastante reduzida em número, além do que, para Sarmiento, ela era nula quanto à capacidade industrial, elemento indispensável à viabilidade da nação. Por isso não haveria como esperar o progresso lento da população natural, o que seria "condenar-se a nulidade por séculos". A América não poderia esperar. O progresso era algo urgente. Além do que crescimento demográfico natural reproduziria os mesmos homens desprovidos de conhecimentos e de noções industriais. A única solução seria lançar mão da imigração européia: a única capaz de melhorar a condição "inteligente, industrial e produtiva da população". Mesclar com a população de paises mais adiantados seria uma forma de introduzir na América suas artes, suas indústrias, sua atividade e sua aptidão ao trabalho. Assim, a imigração era vista como elemento de prosperidade, de progresso e de engrandecimento da América. A ordem era povoar o país e criar riquezas. Que esses imigrantes pudessem fazer aqui o mesmo que fizeram no norte da América. Mas aqui o concurso deles era ainda mais importante, pois os norte-americanos já eram descendentes de uma tradição industrial e manufatureira herdadas da Inglaterra, já continham em seu sangue os elementos de desenvolvimento, riqueza e civilização. Interessante que essa América de imigrantes poderia superar em riqueza a própria Europa. Era preciso recuperar o tempo perdido. O odiado espírito de "americanismo" para Sarmiento era o que os governos argentinos, especialmente sob Rosas, haviam incentivado como um espírito de antipatia e ódio por tudo que fosse europeu. Para garantir uma situação tranqüila para esses estrangeiros era preciso eliminar esse "ranço" americanista. Sarmiento considerava americanismo como sinônimo de barbárie. Nesse sentido, a pátria argentina não seria uma pátria de americanos, mas uma nação de todos os europeus. Construir uma nação era antes de tudo povoar a região do Prata com imigrantes europeus.

Mas para constituir o estado-nação um dos requisitos preliminares seria definir também suas fronteiras geográficas - e também étnicas. Por isso Sarmiento tanto se preocupou em definir e organizar as fronteiras geográficas, tarefa que deveria ser desempenhada principalmente pelo exército. No entanto, mais do que uma fronteira geográfica, tratava-se de alargar uma fronteira étnica, já que a principal função dos militares era "proteger" e desinfestar a fronteira dos elementos "selvagens". 
Desde Bahia Blanca hasta la cordillera de los Andes, apoyándose en la margen del rio Colorado, debe de diez en diez leguas erigirse un fuerte permanente, y dispuesto de modo que sirva de núcleo a una ciudad. Esto no haria mas que quince a veinte fuertes, los cuales formarian un limite final a la República por el Sud. Las tribus salvages que quedasen cortadas por esta linea de puestos avanzados, no resistirán largo tiempo a la amenaza de ser aniquiladas, cogidas entre dos fuerzas y diezmadas. (p. 97)

Note-se aqui que, se para o gaúcho ainda restava a possibilidade de, através da educação, fazer parte da nova nação, os indígenas deveriam se conformar em ficar do outro lado da fronteira. A nação sarmientina não incluía os povos indígenas, nem sequer como coadjuvantes. $O$ exército cuidaria, pelas armas, de garantir essa fronteira geográfica, que mais do que dois territórios, deveria separar dois campos étnicos e culturais.

Além desse trabalho de reorganização do espaço nacional, de redefinição de fronteiras, haveria que dar à nova nação um modelo constitucional capaz de assegurar a prosperidade e o bem comum. $\mathrm{O}$ modelo a seguir seria a Constituição dos Estados Unidos. No entanto, para Sarmiento, todas constituições poderiam reduzir-se a uma só: aquela que proclama os direitos e obrigações do homem na sociedade. Elas, as constituições, por si só, não garantem a ordem. O que garantiria a ordem seriam os "interesses comprometidos", ou seja, o comércio por todas as partes. Por isso não haveria qualquer possibilidade de progresso em um país despovoado e sem indústria. Não haveria, nestas circunstâncias, como conter o "caos".

Em tom profético nosso intelectual entoa um hino de otimismo exacerbado quanto ao futuro magnífico da Argentina. Era preciso levantar o moral dos povos do Rio da Prata, infundir entre eles o mesmo espírito de otimismo. Fazê-los crer que estavam, pela Providência, predestinados a formar uma grande nação. Qualquer estrangeiro que chegasse às praias argentinas dotado dos valores da civilização seria bem recebido e considerado também "argentino". A pátria argentina de Sarmiento é a pátria de todos os homens civilizados da terra. O futuro eram os Estados Unidos da América do Sul. 
¿Dirásenos que todos estos son sueños? Ah! Sueños en efecto; pero sueños que ennoblecen al hombre, y que para los pueblos basta que los tengan y hagan de su realizacion el objeto de sus aspiraciones, para verlos realizados. Sueño, empero, que han realizado todos los pueblos civilizados (...) La civilización, armada hoy de los instrumentos de poder que há puesto en sus manos la ciencia, los lleva consigo donde quiera que penetra. (p. 75)

Sarmiento certamente se perguntava: não teríamos nós também o direito aos nossos próprios sonhos? Talvez aqui tenhamos, pelo menos no que a escritura apresenta de forma explícita, o momento de maior reflexão utópica. $\mathrm{O}$ alimentar dessa aspiração pela concretização efetiva dos sonhos é fator constitutivo de primeira ordem das utopias. Ainda mais que a idéia é reforçada não só pelo "exemplo" de outros povos, mas sobretudo pela fé e esperança de que, para aqueles dotados das armas da ciência e da razão, muitos sonhos se tornavam possíveis.

\section{O Que Fazer com o Existente?}

Como já dissemos antes, o projeto utópico sarmientino de construção de uma nação está assim tomado pela metáfora do deserto: deserto que significa ausência, privação, vazio. Vazio de habitantes, mas também de história, de formas civilizadas, de poder, de razão e, de identidade. Sarmiento confessa várias vezes seu ardente desejo de constituir sua pátria. Mas sua pátria natal incorpora elementos de outras pátrias civilizadas. A nova identidade nacional seria algo a ser construído, num processo que inclui a caracterização, a negação e eliminação das demais identidades. Nesse sentido seu projeto de nação é dicotômico em vários sentidos. Leva consigo uma série de oposições binárias: civilizado-bárbaro, patriota-traidor, racional-irracional, cheio-vazio, ordem-caos, união-federação, cidade-campo, progresso-atraso, pazguerra etc. Adriana Pérsico (1993) explora muito bem tais dicotomias, ressaltando que mais do que uma "utopia", o "não-lugar", trata-se de uma "eutopia", do "bom-lugar", pois nas escrituras sarmientinas coexistem num mesmo espaço as duas ordens binárias e contraditórias: uma realidade presente enferma, degradada, bárbara, e outra que constitui o modelo perfeito potencial, civilizada. Segundo Pérsico, é como se 
cada elemento, para se constituir, necessitasse do reconhecimento e presença de seu contrário. Cada termo extrai seu valor por oposição ao outro: é o que o outro não é. (1993: 89) O modelo ideal carece então de uma harmonia que não admite o discordante, o oponente. São peças que não se encaixam na estrutura estrategicamente planificada à luz da razão. Nesse sentido o modelo é essencialmente excludente, só vinga mediante a eliminação do seu contraponto, ou quando muito à sua sujeição. $\mathrm{O}$ fator primordial que garantiria as exclusões seria assim a presença ou ausência de razão. A irracionalidade seria o obstáculo máximo para que se tivesse um lugar nesse projeto. O outro é, antes de tudo, um irracional. Presente aqui uma visão maniqueísta típica dos intelectuais dessa época, que enfatizavam o enfrentamento entre razão e sem-razão. É nesse contexto em que se coloca a questão do outro, que era antes de tudo tachado de anti-patriota. Seria aquele que estaria além da fronteira da razão. Quanto aos indígenas, bárbaros por natureza, eram uns selvagens irrecuperáveis. Sua exclusão da nação deveria ser total: tarefa do exército. Seu aniquilamento físico era mesmo necessário à pátria nacional. A definição das fronteiras do novo Estado-nação eram mais que geográficas, como já dissemos, eram antes de tudo, no que diz respeito aos indígenas, fronteiras étnicas que tinham a função de dividir dois mundos, duas culturas. Restava o gaúcho e sua cultura, que não podendo ser de vez excluído, deveria ser, na medida do possível, incorporado. À civilização competia dissolver as heterogeneidades. Para não ser acusado de anti-patriota só restava ao gaúcho esquecer sua própria identidade, que deveria ser apagada. Em seu lugar deveria assimilar uma cultura alheia, transfigurar-se e assumir uma nova identidade. Deveriam ser educados na nova cultura, assim como as crianças, segundo o princípio imposto da obediência cega. Para Sarmiento era impossível conciliar um povo selvagem e um civilizado. Desta forma se encontrava a resposta para o que fazer com a velha realidade herdada da colônia, povoada mais de vacas que de seres humanos. Excluir, pela educação ou pelas armas.

Mas se Sarmiento preocupava-se tanto em construir uma nação, sua idéia de nacionalidade era bastante peculiar. Num mesmo artigo já citado de $1856^{\circ}$ ele desenvolve a idéia de que os povos e culturas autóctones da América não tinham qualquer apego à nacionalidade, tendendo para a dissolução. Já as raças cultas e civilizadas, por sua vez, 
levavam consigo a nobre propensão para a nacionalidade. Esse sentimento estaria menos desenvolvido entre os povos bárbaros. Daí resulta que, assim como a própria Independência foi obra dos espanhóis, a construção da nova nação só poderia ser obra daqueles que realmente se apegavam ao sentimento nacional. Contraditoriamente, este seria um elemento predominantemente externo, a ser trazido e implantado nas terras do pampa. Assim como o próprio Sarmiento, os verdadeiros patriotas não se encontravam na pátria.

Argirópolis resume-se assim num texto que propõe, acima de tudo, a fundação de um estado-nação. Seu texto reflete uma "utopia da unificação" (Rodriguez Pérsico, 1993: v) Sarmiento se coloca na vanguarda e daí formula o que deve ser e o que não deve ser o deserto argentino. O eutopos, "bom-lugar" teria já um exemplo, transformado em modelo: os Estados Unidos da América do Norte. ${ }^{10}$ Sua argumentação aqui é nesse sentido historicista, ou, do apego ao exemplo histórico concreto, que deu certo. Em Argirópolis estarão os elementos caracterizadores dessa "boa sociedade".

\section{Entre sinédoques e metonímias}

Não é necessário uma leitura muito atenta de Argirópolis para detectar a presença nítida do binômio crítica-proposta, característico dos projetos utópicos e bem explorado por Guldberg. São nítidos os fins um estado nacional dotado de grandeza material - e os meios confederação, congresso constituinte, capital neutra etc. - propostos. Ao menos do ponto de vista formal, da sua estrutura, não há dúvidas que este texto constitui-se num belo exemplar do gênero utópico na América. No entanto, a crítica, assim como a proposta, não pode ser reduzida a uma mera crítica de cunho liberal, como pode parecer a primeira vista. É verdade que o textual na escritura sarmientina vai muito pouco além de um "panfleto político liberal". Uma leitura mais atenta do texto, um exame minucioso de suas entrelinhas revela, por parte do escritor-utopista um domínio exemplar da arte do discurso. Seu texto está infestado de figuras de linguagem tais como metáforas, metonimias - transferência do nome de um elemento para outro, em vista de uma relação de causalidade ou implicação mútua -, sinédoques - transferência do nome de um elemento a outro, em vista de uma relação de contiguidade, ou de 
proximidade entre ambos, entre outras. Tais figuras exigem do leitor uma reflexão que leve em conta ainda o extratextual, que leve em conta inclusive outras obras do mesmo autor, para uma perfeita compreensão da mensagem. É sabido que os livros de Sarmiento sempre tinham um propósito muito claro, um fim utilitarista. No entanto. muitas vezes o espaço textual dedicado no texto não é proporcional à importancia outorgada a um elemento específico. A consagração da metonimia se encontra por exemplo em seu célebre Factundo $(1845)$. Ao se propor a elaborar uma biografia de um caudilho. Facundo Quiroga. o also era outro. Visava em última instância descrever a realidade da vida argentina. a maneira de ser do povo das campanhas, embora esse mundo se revelasse na história de vida do caudilho. Há aqui uma relação de implicação: Facundo é o produto da barbárie. Falemos de Facundo para revelar a barbárie. E em Argirópolis? Aqui a metáfora que guia o texto é a do deserto e a sinédoque por excelência é a própria Argirópolis. Como bem observou Guldberg (1991, p. 76), a ilha não resume toda a utopia. O verdadeiro topos da utopia seria a região formada pelo antigo ViceReinado do Rio da Prata. A ilha seria apenas o significante maior da unidade de toda a federação. A síntese não só para por fím às particularidades e inimizades, mas a sintese de um novo "modo de vida" que deveria, pelas marés da cultura ribeirinha, invadir e fecundar o deserto com civilização. Sob o manto da "neutralidade" que envolve a justificativa de Martín García, se propunha a hegemonia de um novo modo de vida que daria sustentação à construção da nova nação. Guldberg falava com muita propriedade da pretensão sarmientina de um Argiropais (1991, p. 75).

Sarmiento, igual a Utopus, quis apoderar-se de uma ilha, nomeando-a. Ambos conquistadores tiveram bastante gênio e lutaram obstinadamente por transformar populações selvagens em povos civilizados. Segundo a "tradição", Utopus separou do continente a antiga região de Abraxa e definiu os limites da sua ilha Utopia. Já aquilo que Sarmiento queria separar, "juntar" e conferir-lhe uma identidade era a nação platina. Assim, o topos da utopia de Sarmiento, que era muito mais uma "eutopia", o "bom lugar", ia além das fronteiras de Martín García: incluía o deserto do continente. 


\begin{abstract}
The present paper explores the utopian content of the book, Argirópolis, written by the argentinean Domingos Faustino Sarmiento (1811-1888). This author aimed to assemble all the area of the old Vice-Reinado do Rio da Prata which included Argentina, Uruguai. Paraguai and part of the present Bolivia. Thus, Sarmiento presents a proposal for the building of a new town called Argirópolis - the Prata's town - in the Martin Garcia island. So, this paper analyses the Sarmiento's utopia where it could be found the idea or the wish of a new nation for the "argentinean desert" or, perhaps, a new identity for the River Plate region.
\end{abstract}

Key-words: Sarmiento; Argirópolis; Argentina; identity.

\title{
Notas
}

1 Esse grupo originou-se no "Salón Literario de Buenos Aires", uma instituição criada pelo livreiro Marcos Sastre em 1837, formada por jovens intelectuais que faziam oposição ao governo de Juan Manuel Rosas. Participavam, entre outros, figuras eminentes tais como Juan Baptista Alberdi e Estéban Echeverría.

2 Cujo território compreendia a Argentina, Uruguai, Paraguai e parte da Bolívia atuais.

3 No quinto capítulo do livro Sarmiento explicará seu neologismo. Junto ao nome Argirópolis ele agrega a seguinte nota: "Para evitar una perifrasis, creamos un nombre técnico, emanado de la naturaleza del objeto denominado, arguriol, argurion, palabra griega, que significa plata, y polis terminación de ciudad. Argirópolis, ciudad del Plata." (p. 68)

4 Horácio Cerutti Guldberg (1991) explora a estrutura de um gênero utópico presente entre a intelligentzia americana no século XIX, e, com base num trabalho de Horkheimer, destaca esses dois momentos que integram sua estrutura: o da crítica e o da proposta. Guldberg empreende um breve estudo sobre o utopismo do século XIX na América, a partir do que ele considerou como dois expoentes do gênero utópico gestados no seio da ideologia liberal: a Argirópolis, de Sarmiento e Peregrinación de Luz del Día, de Juan Baptista Alberdi. 
5 Quando não houver referência à outra obra de Sarmiento, as citações se referem ao texto de Argirópolis, conforme a edição indicada na bibliografia.

6 Heloisa Reichel e Ieda Gutfreind (1995) sustentam em recente publicação a tese de que pelo menos no ambiente geofísico do pampa, constituiu-se uma área onde por um longo período se realizaram trocas comerciais e culturais, em função principalmente da atividade pecuária, que teria possibilitado vivências sociais concretas expressas fundamentalmente numa cultura gaúcha.

$7 \mathrm{Na}$ introdução à coletânea de textos de Sarmiento (ver referências bibliográficas).

8 Obras completas, $t$. XVII p. 25-7. Artigo: Hechos e repulsiones que han preparado la federación argentina. El Nacional. 13 dez. 1856. (Citado por PÓMER, 1983, p. 63-64)

9 Obras completas, t. XVII p.25-7. Artigo: Hechos e repulsiones que han preparado la federación argentina. El Nacional, 13 dez. 1856. (Citado por PÓMER, 1983, p. 63-64)

10 Segundo Pómer (1983, p. 16), Sarmiento, assim como a geração de 37 , teria se deslumbrado com a descrição de Tocqueville da sociedade norte-americana, particularmente no que diz respeito a sua vida comunitária. Mais tarde Samriento ratificará com os próprios olhos tais impressões.

\section{Referências bibliográficas}

AINSA, Fernando. De La Edad de Oro a El Dorado: génesis del discurso utópico americano. México, D.F.: Fondo de Cultura Económica, 1992. (Col. Tierra Firme)

CERUTTI GULDBERG, Horacio. Presagio y tópica del descubrimiento. México, DF: Universidad Nacional Autónoma de México, 1991. (Col. 500 años después)

MORE, Thomas. A Utopia. Trad. Luís de Andrade. São Paulo: Abril Cultural, 3. ed., 1984. (Col. Os Pensadores)

POMER, León. (Org.) D. F. Sarmiento: política. Trad.: Vicente Cechelero. São Paulo: Ática, 1983. (Grandes Cientistas Sociais; 35) 
REICHEL, Heloisa Jochims e GUTFREIND, leda. Fronteiras e guerras no Prata. São Paulo: Atual, 1995. (Col. Discutindo a História do Brasil)

RODRIGUEZ PÉRSICO, Adriana. Un huracán llamado progreso: utopia y autobiografia en Sarmiento y Alberdi. Washington: OEA/ OAS, 1993. (Col. INTERAMER, n. 22)

SARMIENTO, Domingo Faustino. Argirópolis o la Capital de los Estados Confederados del Rio de la Plata. In Obras de D. F. Sarmiento. Buenos Aires, Editadas por A. Belin Sarmiento, publicadas bajo los auspicios del gobierno argentino, 1896, Tomo XIII.

SARMIENTO, Domingo Faustino. Conflicto y armonía de las razas en América - Conclusiones. In ZEA, Leopoldo (Compilador). Fuentes de la Cultura Latinoamericana. México: Fondo de Cultura Económica, 1993, Tomo I, p. 401-411.

SARMIENTO, Domingo Faustino. Facundo o civilización y barbarie en las pampas argentinas. Buenos Aires: Centro Editor de América Latina, 1979. 